\title{
Entre estrangeiros e nacionais: agentes públicos e o ideal de trabalhador na propaganda e legislação nos primeiros anos da República no Pará
}

\author{
Francisnaldo Sousa dos Santos* \\ Francivaldo Alves Nunes*
}

\section{3}

Resumo: O objetivo deste artigo é evidenciar, das mais variadas formas e fontes documentais, como os relatórios dos presidentes da província, as mensagens dos governadores e a legislação cunhada entre o final do século XIX e o início do século $X X$, a preferência dos agentes públicos pelo trabalhador estrangeiro em detrimento do colono nacional para o desenvolvimento da produção agrícola no Pará nos anos iniciais da República. Além de uma legislação que privilegiava o imigrante, era realizada uma intensa propaganda na Europa com o objetivo de seduzir esse trabalhador. A proposta é apontar que os discursos oficiais exaltavam as qualidades dos estrangeiros, apontando-os como alternativa para alavancar a agricultura no interior dos espaços agrícolas responsáveis pelo abastecimento da capital do Pará.

Palavras-chave: trabalhadores estrangeiros e nacionais; agricultura; legislação e propaganda.

Summary: The purpose of this article is to highlight the most varied forms and documentary sources, such as the reports of the presidents of the province, the messages of the governors and the legislation coined between the end of the nineteenth century and the beginning of the twentieth century, the preference of public agents for the foreign worker to the detriment of the national settler for the development of agricultural production in Pará in the early years of the Republic. In addition to legislation that privileged the immigrant was carried out an intense propaganda in Europe with the aim of seducing this worker. The proposal is to point out that the official speeches exalted the qualities of foreigners, pointing them as an alternative to leverage agriculture within the agricultural spaces, responsible for supplying the capital of Pará.

* Doutorando em História Social pelo Programa de Pós-Graduação em História Social da Amazônia pela Universidade Federal do Pará (2017). E-mail: francisnaldosousa@hotmail.com.

** Doutor em História Social pela Universidade Federal Fluminense (2011), com estágio pós-doutoral pela Universidade Nova de Lisboa (2014) e professor da Universidade Federal do Pará. 
Keywords: foreign workers and nationals; agriculture; legislation and propaganda.

\section{Introdução}

Quando assumi a administração d'esta província ordenei ao thesouro provincial que me enviasse uma demonstração do estado dos cofres públicos, e por ella verifiquei que não era próspera a situação financeira da província, havendo um déficit de 506 contos, não comprehendendo o que estava em débito por liquidar.

(...)

A safra da borracha, que foi abundante, poude desembaraçar o thesouro, que não obstante os graves encargos, que sobre elle pesava ... ${ }^{1}$

A fala do presidente da província do Pará, Joaquim da Costa Barradas, no relatório com o qual passou o cargo de chefe de governo a Francisco José Cardoso Júnior, é reveladora do contexto histórico vivenciado não apenas no Pará, mas na própria região amazônica entre o final do século XIX e início do século XX. Assim como a fartura na safra da borracha contribuía para manter equilibradas as contas dos governos provincial e estadual, os lucros com a exportação desse produto foram responsáveis também pela viabilização de diversos projetos para a região, como os programas de colonização e imigração. Em outras palavras, as receitas desse extrativismo viabilizaram um projeto de povoamento, a partir da criação de núcleos coloniais, ao longo da chamada Zona Bragantina, região nordeste do Pará, sempre privilegiando o trabalhador estrangeiro visto como sujeito mais afeito ao trabalho e conhecedor de técnicas agrícolas que seriam importantes para o desenvolvimento da agricultura não só no Pará, mas na região amazônica de um modo geral.

Dentro dessa perspectiva de fomento à produção agrícola, o extrativismo gomífero na Amazônia se apresentava como alternativa tão importante para a economia local que Franciane Gama Lacerda chega a afirmar que, além de ser responsável pelo desenvolvimento de centros urbanos como Manaus e Belém, foi responsável também pelo "atrelamento da Amazônia ao capitalismo internacional". ${ }^{2}$ Ainda sobre essa questão, Leandro Tocantins vai um pouco mais além dos avanços arquitetônicos promovidos pela economia gomífera e destaca que a "borracha vinha transformar a sociedade amazônica, a começar pelo modo de ser individual", assim como não deixava de enfatizar que esses valores vinculados à ideia de modernização extrapolavam os limites dos centros urbanos, estendendo-se para áreas rurais do Pará e do Amazonas. ${ }^{3}$

Essa riqueza também foi responsável por financiar os projetos de colonização, desde a criação de núcleos coloniais até a vinda e instalação de imigrantes, especialmente europeus. Desde a criação do núcleo colonial de Benevides, em 1875, a região Bragantina passou a receber inúmeros colonos de diversas

1 PARÁ. Relatório com que o Exmo. Sr. Desembargador Joaquim da Costa Barradas passou a administração da província ao Exmo. Sr. Conselheiro Coronel Francisco José Cardoso Junior. Belém: Typ. do Diário de Notícias, 1887, p. 15.

2 LACERDA, Franciane Gama. Nos Trilhos da Modernidade: instalação da Estrada de Ferro de Bragança (1870/1907). (Monografia de conclusão de curso em Licenciatura e Bacharelado em História, UFPA, 1992), p. 24.

3 TOCANTINS, Leandro. Amazônia: natureza, homem e tempo. Rio de Janeiro: Conquista, 1960 (Coleção Temas Brasileiros), p. 160. 
nacionalidades. Diferentes comportamentos e valores se mesclaram no interior da floresta e nas ruas da movimentada Belém, ajudando a compor um cenário que se ajustava à nova realidade cotidiana do belenense. Diversos espaços agrícolas foram criados e povoados, não apenas por estrangeiros, mas também por um número significativo de colonos nacionais. ${ }^{4}$

A proposta deste artigo é mostrar que os agentes públicos, provinciais e republicanos, buscaram alternativas de fomento à produção agrícola por meio de uma almejada modernização do campo. Essa pretensa modernização se daria pela entrada de imigrantes europeus na província e, posteriormente, no estado do Pará, com sujeitos vistos como capazes de desenvolver a agricultura local com base não somente no conhecimento de novas técnicas, assim como na disposição para o trabalho, deixando à margem o colono nacional visto muitas vezes não apenas como um trabalhador com pouca afeição à lida no campo, mas também como usuário de técnicas arcaicas de produção. Essa predileção pelo trabalhador estrangeiro em detrimento do trabalhador nacional ficou evidenciada não só nos discursos oficiais, mas também na própria legislação cunhada nesse contexto de transição do Império para a República no Pará.

Para a construção das análises do presente artigo, utilizamos, entre outras fontes, os relatórios, falas e mensagens dos presidentes e governadores à Assembleia Provincial e Legislativa, respectivamente, até para entender como se constituiu esse processo de implantação dos núcleos coloniais a partir da década de 1870, tendo como primeira experiência a colônia de Benevides. Outra possibilidade de comparação que essa fonte oferece é a de relacioná-la com a própria legislação. A letra da lei se apresenta como uma importante fonte na medida em que mostra como deveriam se dar as relações sociais dentro daquele contexto e entre os sujeitos diretamente relacionados a ela, ou seja, a legislação "conduz à compreensão das relações sociais em determinada sociedade, tempo e lugar". 5

\section{Um dilema na agricultura: apostar na quantidade ou na qualidade dos trabalhadores para a lavoura paraense?}

Olhando para as entrelinhas da legislação gestada nos anos finais do Império e, principalmente, na primeira década republicana no Pará, inferimos que, nesses dois momentos, os anseios das autoridades estavam muito mais voltados para a quantidade de trabalhadores a serem introduzidos na Zona Bragantina, por isso

4 A presença de retirantes na Amazônia, principalmente de cearenses, é caracterizada pelos distintos momentos que as duas regiões viviam entre o final do século XIX e início do XX. A esse respeito, a pesquisadora Franciane Gama Lacerda destaca que no Pará experimentava-se "um grande crescimento econômico"; os cearenses, nesse mesmo período, viviam em meio a "crises políticas, declínio da produção agrícola e, sobretudo, grandes secas". Ver: LACERDA, Franciane Gama. Migrantes cearenses no Pará: faces da sobrevivência. Belém: Ed. Açaí, 2010, p. 17. Por sua vez, o pesquisador Francivaldo Alves Nunes aponta que, se havia interesse das autoridades públicas paraenses em receber retirantes em virtude da necessidade de mão de obra para a extração do látex, havia por parte das autoridades cearenses interesse em enviá-los, pois "se aglomeravam nos centros urbanos". Ver: NUNES, Francivaldo Alves. "Sob o signo do moderno cultivo: Estado imperial e agricultura na Amazônia". (Tese de doutorado, Universidade Federal Fluminense, 2011), p. 311.

5 MACHADO, Marina Monteiro; MOTA, Maria Sarita. Legislações e terras. In. MOTTA, Marcia; GUIMARÃES, Elione. Propriedades e disputas: fontes para a história do oitocentos. Guarapuava: Unicentro, 2011; Niterói, EDUFF, 2011, p. 253. 
a intensa propaganda de incentivo à imigração, bem como o grande número de núcleos coloniais criados nesse período, sobretudo na República. A ideia de introduzir no Pará um grande número de trabalhadores estrangeiros resolveria, nesses dois períodos, duas importantes questões: uma delas é a quantidade de trabalhadores necessários para promover o povoamento dos espaços agrícolas criados ao longo da região Bragantina e a outra seria o conhecimento técnico que chegaria com esse imigrante, visto como conhecedor de modernas técnicas de cultivo. Essa mudança de perspectiva - da quantidade para a qualidade -, ou seja, do objetivo de necessariamente povoar essas áreas, ocorreu apenas a partir da segunda década do novo regime, quando a preocupação dos agentes públicos estava muito mais voltada para a qualificação técnica desse trabalhador rural e do uso racional do solo. Essa quebra de paradigma ocorreu nos governos de Augusto Montenegro (1902-1909) e João Coelho (1909-1913).

Acerca dessa questão, o pesquisador Carlos Leandro Esteves afirma que essa mudança de paradigma dentro do programa de colonização republicano se dá de fato a partir do governo de Augusto Montenegro, quando o mesmo

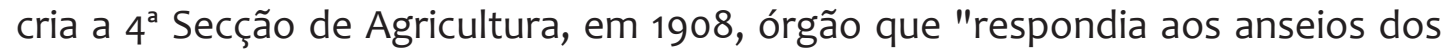
setores patronais rurais paraenses na medida em que inscrevia no interior da Secretaria de Obras Públicas, Terras e Viação uma seção exclusiva, e gozando de significativa autonomia, para tratar de questões referentes à terra em suas variadas dimensões". ${ }^{6}$ Essa transformação na forma de pensar a agricultura no Pará se estendeu também para o governo de João Antônio Coelho. Em síntese, houve então uma mudança nas "sucessivas políticas de estímulo e subsídio à vinda de imigrantes estrangeiros de várias nacionalidades para trabalhar na lavoura, práticas adotadas a partir da segunda metade do século XIX" para a realização de projetos que "buscavam enfatizar a necessidade de um aumento da produtividade do solo e da racionalização de seu uso e ocupação".?

Desde a segunda metade do século XIX, já havia por parte dos governantes paraenses uma forte apreensão quanto ao desenvolvimento da agricultura, principalmente diante da falta de trabalhadores. ${ }^{8}$ Essa escassez se dava em decorrência, de acordo com as autoridades públicas, da saída de trabalhadores que antes se dedicavam à agricultura e passaram a voltar-se à extração de madeira ou do látex, o que provocava, por sua vez, uma séria carência de gêneros agrícolas, especialmente na capital Belém. No entanto, deve-se esclarecer que o sujeito que trabalhava no extrativismo também se dedicava à agricultura e viceversa. Ou seja, essas atividades não raras vezes eram realizadas de forma paralela. De certa forma, a agricultura, mesmo antes da implantação daquele novo regime político, como assevera Francivaldo Alves Nunes, já era vista como "responsável em promover a prosperidade e a grandeza futura da província". ${ }^{9}$ Por isso mesmo,

6 ESTEVES, Carlos Leandro. "A 'Reconstrução radical da agricultura': ocupação, propriedade e produtividade nas políticas públicas dos governos do Pará (1901-1902)". In: XXVIII SIMPÓSIO NACIONAL DE HISTÓRIA Lugares dos Historiadores: velhos e novos desafios, 2015, Florianópolis/SC, p 1-16 (Anais eletrônicos), p. 2.

7 ESTEVES. "A Reconstrução radical da agricultura", p. 3.

8 Deve-se, contudo, observar que não se tratava necessariamente da falta de trabalhadores, ou seja, embora as autoridades destacassem uma escassez de mão de obra para a agricultura, havia ao mesmo tempo uma marginalização não só do caboclo, o nativo da região, mas também do retirante que fugia das consequências políticas, econômicas e sociais provocadas pelas secas que assolavam a atual região Nordeste do país.

9 NUNES, Francivaldo Alves. Modernidade, agricultura e migração nordestina: os discursos e a atuação governamental no Pará do século XIX. Revista eletrônica Cadernos de História. Publicação do corpo discente do Departamento de História da Universidade Federal de Ouro Preto. Ano II; n. 1; março de 2007 , p. 2. 
o fomento à produção agrícola ganha a atenção das autoridades com destaque para o trabalhador estrangeiro.

Quanto a essa dicotomia quantificação/qualificação do trabalhador rural, Marília Ferreira Emmi confirma a tendência das autoridades provinciais em atrair o máximo de trabalhadores agrícolas ao destacar que "durante o Império, a articulação da imigração ao povoamento do território fez com que os temas da imigração e colonização estivessem nos dispositivos legais sempre relacionados". ${ }^{10}$ Por outro lado, quanto ao período republicano, a mesma autora ratifica a afirmativa feita acima quanto aos elementos de criticidade que se apresentam na legislação pós-1889. Segundo ela,

a legislação sobre imigração no período republicano - iniciado em 1889 - parte de uma crítica das diretrizes anteriores considerando que o projeto colonizador do Império ao localizar as colônias agrícolas não atentava para as consequências que adviriam do isolamento de estrangeiros em pontos estratégicos do território nacional. ${ }^{11}$

O declínio da agricultura, observável nas áreas afastadas de Belém, motivado pela escassez de mão de obra como apontavam as autoridades, afetava diretamente a oferta de produtos nos mercados da capital, uma vez que estavam interligados. Nesse sentido, Elis Regina Vieira e Franciane Gama Lacerda afirmam que "problemas que se gestavam nos espaços rurais ou em áreas de floresta acabavam se conectando com a cidade de Belém quando interferiam, por exemplo, no abastecimento dos moradores da capital paraense". ${ }^{12}$ Para povoar esses espaços, a administração provincial apostava no trabalhador estrangeiro. A justificativa para essa preferência se baseava nas vantagens que chegariam à província juntamente com esse colono. De acordo como o modo de pensar dos presidentes da província do Pará, fossem eles liberais ou conservadores, que deram início ao projeto de colonização da região Bragantina, o estrangeiro conhecia técnicas modernas de produção, além de ser considerado afeito ao trabalho e assim servir de exemplo para os trabalhadores locais, como já havia deixado claro o presidente da província do Pará, Pedro Leão Veloso, em 1867. ${ }^{13}$

Com o advento da República, a agricultura seguiu tendo uma atenção especial por parte dos dirigentes estaduais. Em mensagem de 1893 encaminhada à Assembleia Legislativa, Lauro Sodré, que governou o estado o Pará entre os anos de 1891 a 1897 e posteriormente entre os anos de 1917 a 1921, lamentou a falta de braços para tocar a lavoura. Ele destacou que o "povoamento do nosso imenso território, em sua quase totalidade, é desaproveitado e inculto". Ratificou o que os antigos presidentes da província já alardeavam, ao afirmar que o Pará possuía "extensas zonas de terrenos feracíssimos, que à mingua de braços estão voltados ao abandono". Por conta dessa situação em que se encontrava o estado, o mesmo reclamou não poder contar com ajuda federal, pois os recursos são "escassos e incertos". Lauro Sodré ainda afirmou que, para resolver esse problema de primeira

10 EMMI, Marília Ferreira. Italianos na Amazônia (1870-1950): pioneirismo econômico e identidade. Belém: NAEA - Núcleo de Altos Estudos Amazônicos, 2008, p. 85.

11 EMMI. Italianos na Amazônia (1870-1950), p. 85.

12 VIEIRA, Elis Regina Correa; LACERDA, Franciane Gama. "O Celeiro da Amazônia: agricultura e natureza no Pará na virada do século XIX para o XX". Revista Topoi, Rio de Janeiro, v. 16, n. 30, p. 157-181, jan./jun. 2015, p. 159.

13 PARÁ. Relatório com que o Exmo. Sr. Presidente da Província, Dr. Pedro Leão Vellozo, passou a administração da mesma ao Exmo. Sr. $1^{\circ}$ Vice-presidente, Barão do Arary, no dia 9 de abril de 1867. Belém: Tip. de Frederico Rhossard, 1867, p. 19. 
ordem, seria necessário "encaminhar para este estado a incessante corrente emigratória, que de anno a anno vai crescendo"..$^{14}$ Ele concluiu o que pensava a respeito desse tema garantindo ser imprescindível o povoamento para que não se continue "vendo em derredor de nós tantas e tantas riquezas naturaes perdidas como um thezouro esquecido pelo homem". De forma até poética e com um tom profético, Lauro Sodré asseverou que o progresso do estado do Pará vai acontecer,

Só quando milhares e milhares de pioneiros houverem palmilhado as nossas terras virgens até aqui de tracto humano; só quando o mineiro audaz rasgar o subsolo para arrancar de lá as preciosidades que jazem desutilisadas e sem valor; só quando a super abundância de braços atirar para a agricultura as grandes sobras dos que vivem da indústria extrativa; só então devemos dormir tranquilos sobre o nosso futuro grande e feliz. ${ }^{15}$

Pensamentos como esse do governador Lauro Sodré deixam evidente que essa preocupação imediata com a ocupação de áreas pouco povoadas mostra ainda resquícios da forma de colonizar que havia sido planejada pelos antigos presidentes. Apesar de ter ocorrido rupturas nos programas de colonização entre os regimes políticos, a primeira década republicana ainda esteve muito voltada para essa questão do número de trabalhadores e não só os muitos núcleos criados ao longo da região Bragantina deixam essa questão evidente, mas também as ações e discursos do governador José Paes de Carvalho, sucessor de Lauro Sodré, corroboram essa afirmativa.

De qualquer forma, na tentativa de buscar explicações para a escassez de trabalhadores na lavoura paraense, o governador Lauro Sodré entendia que a indústria extrativa muito contribuía para a riqueza do estado, mas lamentava "que tal crescimento tenha sido feito com prejuízo da agricultura em estado evidente de pobreza". ${ }^{16}$ Para tentar alavancar a agricultura, o governador sugeriu então aos membros da Assembleia Legislativa a criação de sindicatos agrícolas como, segundo ele, já existiam na França, Alemanha, Itália, Hungria e Estados Unidos. Com a criação desses sindicatos agrícolas, a expectativa do governador era de que "a cooperação dos lavradores possa encorajar todos os melhoramentos que nunca lograrão conseguir esforços dispersos, interesses dissociados". ${ }^{17}$

A falta de trabalhadores agrícolas era de fato o grande problema que atuava contra os interesses do governo. Uma série de contratos assinados com o objetivo de introduzir imigrantes acabou fracassando tanto no Império quanto na República. Conforme afirma Franciane Gama Lacerda, essa preocupação estava evidente especialmente "nos pronunciamentos oficiais que se dividiam entre a utilização de trabalhadores nacionais e o incentivo à vinda de imigrantes estrangeiros". A autora ainda destaca que o governador José Paes de Carvalho acreditava que o imigrante poderia auxiliar os trabalhadores nacionais dando-Ihes um caráter mais profissional às suas atividades. Essa forma de pensar foi responsável pela "formação de vários núcleos coloniais às margens da Estrada de Ferro de Bragança, em que conviveram franceses, portugueses, espanhóis e cearenses...". ${ }^{18}$

14 PARÁ. Mensagem dirigida pelo Sr. Governador, Dr. Lauro Sodré, ao Congresso do Estado do Pará, em $1^{\circ}$ de fevereiro de 1893. Belém: Typ. do Diário Official, 1893, p. 22.

15 PARÁ. Mensagem dirigida pelo Sr. Governador, Dr. Lauro Sodré, ao Congresso do Estado do Pará, em $1^{\circ}$ de fevereiro de 1893, p. 23.

16 Idem, p. 26.

17 PARÁ. Mensagem dirigida pelo Sr. Governador, Dr. Lauro Sodré, ao Congresso do Estado do Pará, em $1^{\circ}$ de fevereiro de 1893 , p. 27.

18 LACERDA, Franciane Gama. Migrantes cearenses no Pará: faces da sobrevivência (1889-1919). Belém: Ed. 
De um modo geral, a agricultura - principal atividade de produção no interior dos núcleos coloniais - obteve um grau de importância durante a fase imperial e que se manteve durante a República, tendo o trabalhador estrangeiro no cerne dessa questão. As ações dos governantes em atrair trabalhadores que ocupassem esses espaços agrícolas, bem como a própria instalação de diversos núcleos, evidenciam claramente essa preocupação nos dois períodos abordados. Apesar da importância da atividade extrativa para a região, fosse de madeira e mesmo de borracha, a preocupação dos agentes públicos sempre esteve voltada mesmo para produção agrícola. A própria extração do látex sofreu inúmeras críticas, fosse por parte dos governantes ou mesmo por parte da elite agrária, pois como afirma Bárbara Weinstein, a elite fundiária não se beneficiou com a demanda pela exportação do principal produto da Amazônia, como registrado em outras economias agrícolas no Brasil, "uma vez que o que constituía o cerne do sistema extrativo de produção eram as relações de troca e não a propriedade rural". ${ }^{19}$

\section{Legislação republicana no Pará: legalização do trabalhador estrangeiro}

A predileção pelo trabalhador estrangeiro ficou expressa também no ordenamento gestado na primeira década republicana, ou seja, nos governos de Lauro Sodré e de José Paes de Carvalho. Quanto a isso, João de Palma Muniz afirma que até o ano de 1894 as questões relativas à colonização e à imigração no Pará não dispuseram de uma legislação específica que tratasse do tema, para que esse problema pudesse ser visto como uma pauta do programa de governo. Para ele, o primeiro passo para uma organização de fato se daria com a "creação de uma lei especial, condensando dispositivos que permitissem uma organização systemática e permanente". ${ }^{20} \mathrm{~A}$ primeira lei nesse sentido a dar uma organização ao tema foi a Lei n. ${ }^{\circ} 223$, de 30 de junho de 1894, que de acordo com o caput autorizou "o governador a promover a introducção de estrangeiros que pretendessem estabelecer-se no Estado, agricultores ou industriaes". ${ }^{21}$ Para o então governador Lauro Sodré, essa lei surgiu como um passo decisivo em direção à solução do problema e escassez de mão de obra no estado do Pará, mas deixou claro que jamais havia se iludido "acerca das grandes difficuldades, à primeira vista insuperáveis, que se nos antolhava ao ter que pôr em execução aquela lei. Tratava-se de um serviço inteiramente novo, que nós íamos crear".22

O legislador teve a preocupação de elencar as pretensas qualidades do imigrante estrangeiro, como "de bôa conduta e aptos para o trabalho", fosse na agricultura ou em "qualquer indústria útil". A preferência era por imigrantes acompanhados por suas famílias, pois certamente essa medida tinha pretensões de afastar a possibilidade de se instalar pessoas sem compromisso de fixação com o local para o qual seria destinado. Para conseguir atraí-los, a citada lei aponta

Açaí, 2010, p. 306-307.

19 WEINSTEIN, Bárbara. A borracha na Amazônia: expansão e decadência (1850-1920). São Paulo: Hucitec/ Edusp, 1993, p. 87.

20 MUNIZ, João de Palma. Estado do Grão-Pará. Imigração e colonização. História e Estatística 1616-1916. Belém: Imprensa Oficial do Estado do Pará: 1916, p. 66.

21 Coleção das Leis Estaduais do Pará dos anos de 1891 a 1900, precedida da constituição política do Estado. Belém: Imprensa Official, 1900, p. 236. (Lei n. ${ }^{\circ} 223$, de 30 de junho de 1894).

22 PARÁ. Mensagem dirigida ao Congresso do Estado do Pará pelo Dr. Lauro Sodré, governador do Estado, ao expirar o seu mandato em $1^{\circ}$ de fevereiro de 1897. Belém: Typ. do Diário Official, 1897, p. 25. 
alguns favores, como a indenização de passagens, dez dias de hospedagem antes de se dirigirem ao núcleo colonial, tratamento médico assegurado por dois anos nos espaços onde se instalarem, e obrigações do Estado, que aparecem como favores ao imigrante, como a gratuidade no transporte e na alimentação até o ponto de destino. ${ }^{23}$

Dentre esses ditos "favores", um dos mais atrativos era o que estabelecia a concessão gratuita de um lote colonial de 25 hectares, em terrenos férteis, em qualquer núcleo colonial, ficando à escolha do imigrante, onde encontraria a mata derrubada para que pudesse começar a plantar e a construir sua casa. ${ }^{24}$ Essa medida acabou alterando o que estabelecia o Decreto n. ${ }^{\circ} 410$, de 8 de outubro de 1891, o qual determinava que as terras devolutas deveriam ser adquiridas pelo colono por meio de compra. Isso revela que a política de colonização na República estava voltada para a fixação imediata do trabalhador estrangeiro e sua consequente permanência em solo paraense.

Além daqueles favores aos imigrantes acima mencionados, fossem eles introduzidos pelo governo ou por particulares e até mesmo por imigrantes espontâneos, a Lei n. ${ }^{\circ} 223$ autorizou o governador a criar núcleos coloniais "nas proximidades dos principaes centros agrícolas do estado". A introdução desses imigrantes dependeria da aquisição por parte do governo de um local no interior para recepção e hospedagem dos mesmos, previsto no artigo nono, assim como a discriminação de lotes em pelo menos um núcleo colonial. O local destinado para servir de hospedaria para os imigrantes foi a antiga Olaria do Outeiro, próximo do igarapé Maguary, mais precisamente da ilha de Caratateua, recebido em 19 de agosto de 1895, cuja regulamentação se deu com o Decreto n. ${ }^{\circ} 131$, de 10 de outubro de 1895. De acordo com o diretor da Repartição de Obras Públicas, Terras e Colonização, era visto como um dos melhores em todo o país. ${ }^{25}$

Marcos Antônio de Carvalho, ao pesquisar sobre a citada hospedaria, chama atenção para sua localização evidenciar um isolamento sanitário, como já era costume em outras regiões do país, pois algumas epidemias que assolavam a Europa "deixavam em alerta as autoridades brasileiras". Contudo, para além da simples preocupação sanitária, também havia uma preocupação com o controle ideológico. O autor cita o "pedido de repatriamento de um imigrante que fazia distribuição de avulsos de propaganda anarquista". ${ }^{26}$ Sobre a Hospedaria de Imigrantes no Outeiro, Ernesto Cruz afirma que "o vasto estabelecimento preencheu, satisfatoriamente, a sua finalidade" e que o "governo deu ao lugar todas as condições necessárias para o conforto dos imigrantes". ${ }^{27}$

Outra lei a dar prerrogativas ao governador para trabalhar em prol da colonização foi a Lei n. ${ }^{\circ} 330$, de 21 de fevereiro de $1896 .{ }^{28}$ Por essa lei, com apenas

23 Esse artigo foi alterado pela Lei $n .^{\circ} 583$, de 21 de junho de 1898.

24 O engenheiro Henrique Américo Santa Rosa, diretor da Repartição de Obras Públicas, Terras e Colonização, apontou em seu relatório do ano de 1897 que o governo deveria oferecer mais do que uma área para que o imigrante construísse sua casa, mas dar a casa já pronta para moradia, visto por ele como algo essencial. Ver: Relatório apresentado pelo diretor da Repartição de Obras Públicas, Terras e Colonização, em 9 de janeiro de 1897. Belém: Typ. do Diário Official, 1987, p. 163.

25 PARÁ. Relatório apresentado pelo diretor da Repartição de Obras Públicas, Terras e Colonização, em 9 de janeiro de 1897. Belém: Typ. do Diário Official, 1987, p. 144.

26 CARVALHO, Marcos Antônio de. A Hospedaria de Imigrantes do Outeiro em Belém do Pará: um mosaico em construção. In.: SARGES, Nazaré, et al. (coord). Portugal e as imigrações da Europa do sul para a América do Sul. CEPESE: Centro de Estudos da População, Economia e Sociedade. Porto, 2014, p. 202-204.

27 CRUZ, Ernesto. Colonização do Pará. Belém: Conselho Nacional de Pesquisa/Instituto Nacional de Pesquisas da Amazônia, 1958, p. 115.

28 Coleção das Leis Estaduais do Pará dos anos de 1891 a 1900, precedida da constituição política do Estado. Belém, Imprensa Oficial, 1900, p. 353 (Lei n. ${ }^{\circ} 330$, de 21 de fevereiro de 1896). 
dois artigos e que alterava a Lei.$^{\circ} 223$, de 30 de junho de 1894 , no artigo quarto, o governador ficava autorizado a introduzir no estado um total de 100 mil imigrantes, incluindo nesse total os 25 mil dos contratos celebrados com Emílio Martins e Francisco Cepeda, em um prazo de 10 anos. Com essa lei foi suprimido o artigo $4^{\circ}$ da Lei n. ${ }^{\circ} 223$, de 30 de junho de 1894 , "que exigia a permanência do imigrante no estado do Pará, pelo menos por três annos". ${ }^{29}$

Sobre essa revogação, o diretor da Repartição de Obras Públicas, Terras e Colonização, Henrique Américo Santa Rosa, em um de seus relatórios, lembrou que as primeiras reclamações com a criação da Lei n. ${ }^{\circ} 223$ vieram por parte do governo italiano, que via uma forma de "coerção por demais vexatória ao espírito de liberdade dos imigrantes, seus conterrâneos". Henrique Américo Santa Rosa ainda destacou que essa supressão foi prejudicial ao serviço de imigração, principalmente no que tange à introdução de imigrantes italianos. ${ }^{30} \mathrm{Com}$ certo tom de repúdio, o citado diretor perguntou se seria justo que o governo continuasse a despender qualquer gasto com imigrantes que nunca pretenderam ficar no estado desde o momento da saída do país de origem; se o governo do Pará não poderia exigir dos mesmos que permanecessem por um tempo determinado no local destinado, não poderia impedir a saída desses imigrantes e muito menos cobrar indenização desses colonos. Conclama que algo deveria ser feito para solucionar esse problema, pois caso contrário o estado continuaria a gastar "em favor da immigração do sul" e critica a propaganda realizada pelos encarregados em promover a imigração para o sul do país contra a imigração com destino ao Pará. ${ }^{31}$

A mais importante lei voltada para o projeto de colonização pensado pelos agentes públicos durante o governo de José Paes de Carvalho foi a Lei n. ${ }^{\circ} 53$, de 21 de junho de $1898,{ }^{32}$ que reorganizou o serviço de imigração e colonização e modificou a legislação precedente. $O$ objetivo do governo estadual ao sancionar a lei era "legalizar a situação de migrantes nacionais e estrangeiros, bem como incentivar, mas ao mesmo tempo disciplinar, os migrantes que pretendiam, espontaneamente ou por meio de contrato, localizar-se no Pará como 'agricultores'". 33 Ao tratar da difícil situação dos cearenses em consequência das constantes secas que assolavam aquele estado, o governador José Paes de Carvalho destacou que o governo recorreu à aplicação da citada lei para socorrer migrantes que aportavam em Belém. ${ }^{34}$ Isso porque, em seus trinta e dois artigos tratou sobre direitos e deveres dos imigrantes e colonos nacionais, bem como dos favores do Estado e das diretrizes para a criação de estabelecimentos agrícolas particulares. No entanto, quanto à organização espacial dos núcleos, a lei determinava que os mesmos tivessem no máximo 300 lotes, sendo apenas um terço desses aos colonos nacionais e o restante aos estrangeiros. Dispositivos legais como esses deixavam claro que a figura do trabalhador estrangeiro, mesmo nos anos finais da década de 1890 , ainda estava muito presente nos projetos de colonização republicanos, como aquele que elevaria a produtividade agrícola no Pará.

29 MUNIZ. Estado do Grão-Pará. Imigração e colonização, p. 70.

30 PARÁ. Relatório apresentado pelo diretor da Repartição de Obras Públicas, Terras e Colonização, Henrique Américo Santa Rosa, em 9 de janeiro de 1897, p. 139.

31 PARÁ. Relatório apresentado pelo diretor da Repartição de Obras Públicas, Terras e Colonização, Henrique Américo Santa Rosa, em 9 de janeiro de 1897, p. 140.

32 A referida lei pode ser encontrada com todos os seus artigos em: MUNIZ, João de Palma. Estado do GrãoPará. Imigração e colonização, p. 79.

33 LACERDA. Migrantes cearenses no Pará, p. 312.

34 PARÁ. Mensagem dirigida ao Congresso do Estado do Pará pelo Dr. José Paes de Carvalho, governador do Estado, em 7 de abril de 1899. Belém: Typ. do Diário Official, 1899, p. 49. 
Chama atenção a alteração feita no artigo $2^{\circ}$ da Lei n. ${ }^{\circ} 223$, de 30 de junho de 1898, que tratou dos favores do governo aos colonos. Os lotes que antes eram gratuitos passaram a ser vendidos ao valor de oito mil réis por hectare, tendo cada lote 25.000 hectares, com 250 metros de frente e 1.000 metros de fundo. Outra mudança importante tratou da preparação prévia do terreno para o primeiro plantio e do adiantamento da construção de uma pequena casa. Antes, a legislação previa apenas a derrubada das árvores, mas a limpeza e a construção da moradia ficavam por conta do colono. Quanto ao fornecimento de alimentos pelo governo, a lei estipulava "ração" integral nos seis primeiros meses e apenas a metade nos seis meses seguintes. Essa alteração, aliada às emancipações dos núcleos coloniais que pôs fim à assistência dada pelo governo aos colonos, promovidas pelos governadores José Paes de Carvalho e Augusto Montenegro, teve como consequência a saída de muitos colonos de seus lotes.

No mesmo ano em que essa última lei foi sancionada, uma série de muitos núcleos coloniais foi criada. Eugênia Gonçalves Égler inclusive afirma que nesse período houve "um novo surto de colonização". A maioria ficou localizada ao longo da Estrada de Ferro de Bragança, entre eles os de Ferreira Pena, Anita Garibaldi e lanetama. Esses dois últimos, de iniciativa particular, após contrato celebrado com o governo estadual, acabaram fracassando principalmente por causa do baixo número de famílias italianas ali instaladas. O governo então assumiu a responsabilidade pelos núcleos coloniais. Como consequência, "a colonização prosseguiu com retirantes cearenses". 35

De um modo geral, podemos inferir que essas legislações que foram sendo gestadas e modificadas, bem como a estrutura dos órgãos de gestão das políticas de colonização, implicaram modificações substanciais dentro do programa de colonização idealizado pela República, inclusive quando comparadas com as realizações idealizadas nas últimas décadas do período provincial. Na primeira década republicana no Pará, surgiu um conjunto maior de núcleos coloniais criados ao longo da região Bragantina, principalmente às margens da Estrada de Ferro de Bragança, evidenciando a questão quantitativa e sua predileção pelo trabalhador estrangeiro, apesar de uma preocupação com o colono nacional presente em algumas falas do governador José Paes de Carvalho. Podemos dizer que, diferentemente das ações pensadas pelos presidentes provinciais, as ações dos dois primeiros governadores estiveram muito mais voltadas a dar uma maior organização em termos legislativos e burocráticos ao serviço de imigração e colonização. A ausência de leis mais gerais até o início do governo Lauro Sodré dá uma dimensão e um entendimento maior a essa evidência.

\section{Seduzindo o imigrante: a busca pelo trabalhador ideal}

O programa de colonização desenvolvido durante o período provincial com o intuito de atrair trabalhadores estrangeiros ao Pará apresentava como uma de suas principais dificuldades os poucos recursos empregados nas despesas com o transporte dos imigrantes do local de origem até a pronta instalação no núcleo colonial. Por sua vez, imposições feitas aos imigrantes como a obrigatoriedade

35 ÉGLER, Eugênia Gonçalves. "A Zona Bragantina no estado do Pará". Revista Brasileira de Geografia. São Paulo, vol. 23, n. 3, (jul./set.), 1961, p. 531-532. 
de fixação no espaço agrícola previamente determinado contribuíram de alguma forma para os poucos resultados alcançados. A escolha do destino, por parte do imigrante, dentro da província representaria um atrativo a mais ao imigrante, como era garantido por outras províncias como São Paulo. ${ }^{36}$

Vale lembrar que todo esse debate acerca do perfil ideal desse imigrante já acontecia desde o período imperial e, apesar dos retirantes, e em sua grande maioria os cearenses, terem sido responsáveis pelo povoamento de muitos desses núcleos coloniais criados ao longo da região Bragantina como Castanhal, Araripe e Ferreira Penna, por exemplo, o trabalhador pretendido para ocupar os núcleos agrícolas sempre foi mesmo o estrangeiro. Essa valorização do imigrante em detrimento do trabalhador nacional se deu por vários motivos. Como já salientamos, o principal desses motivos era a expectativa de que o estrangeiro, além de novos conhecimentos, traria também novas técnicas de produção desenvolvidas na Europa ou nos Estados Unidos, o que impulsionaria a agricultura local. Esse pensamento, obviamente, nos permite entender que não somente as técnicas usadas pelos colonos nacionais seriam rudimentares, como os próprios trabalhadores locais eram vistos como pouco afeitos ao trabalho agrícola e que, portanto, seriam estimulados pelos estrangeiros.

Essa ideia acerca das pretensas qualidades do trabalhador estrangeiro, cristalizada pela maior parte das autoridades governamentais da segunda metade do século XIX e primeira década da República no Pará, bem como pela própria elite brasileira, de que apenas os europeus poderiam dar à agricultura o desenvolvimento necessário para o aumento da produtividade, é de fato uma visão de mundo preconceituosa. Deve-se levar em consideração também o fato de que a agricultura de subsistência tinha uma importância fundamental não apenas para a economia da Amazônia ou do Pará de modo específico, como para a própria economia brasileira em geral.

Quando, por exemplo, o presidente da província, Pedro Leão Velozo, ainda na década de 1860, afirmava que "o trabalho assíduo, constante e intelligente" era essencial para o progresso de um país e que esse trabalhador tinha que ser um europeu, ficaram claras as intenções do governo em investir na imigração europeia. Em seu relatório, o mesmo presidente acrescentou que os estrangeiros serviriam de exemplo para os trabalhadores locais. Uma das primeiras medidas do então presidente foi a celebração de contrato para a entrada de norte-americanos no Pará, mais precisamente no município de Santarém, instalados na colônia Bom Gosto, construída entre 1866 e $1867 .{ }^{37}$ Essa preferência por estrangeiros não era uma prerrogativa apenas da província do Pará. No Maranhão, por exemplo, foram também criados núcleos com estrangeiros. De acordo com Regina Helena Martins de Faria, "durante todo o oitocentos, o imigrante europeu foi o trabalhador desejado". ${ }^{8}$ Mas, da mesma forma como ocorreu no Pará, a experiência com esses colonos no Maranhão constituiu um completo fracasso, pois os trabalhadores nacionais foram responsáveis pela ocupação do solo nessas regiões.

O presidente Francisco José Cardoso Júnior, fazendo uma avaliação do trabalho realizado na administração do presidente da província Tristão de Alencar

36 BEIGUELMAN, Paula. A crise do escravismo e a grande imigração. 3 ed. São Paulo: Editora Brasiliense, 1982.

37 PARÁ. Relatório com que o Exmo. Sr. Presidente da Província, Dr. Pedro Leão Vellozo, passou a administração da mesma ao Exmo. Sr. $1^{\circ}$ Vice-presidente, Barão do Arary, no dia 9 de abril de 1867. Belém: Tip. de Frederico Rhossard, 1867, p. 19.

38 FARIA, Regina Helena Martins de. Mundo do trabalho no Maranhão oitocentista: os descaminhos da liberdade. São Luís: Edufma, 2012, p. 251. 
Araripe, que criou um núcleo distante quase 60 quilômetros da capital Belém, às margens da Estrada de Ferro de Bragança, com o objetivo de ali instalar imigrantes portugueses, 39 lamentou que "os resultados conseguidos não corresponderam à altura dos sacrifícios feitos, e até agora, além da tentativa infructífera dos colonos açorianos, nenhuma medida de alcance prático fora tomada pela administração". 40 A sugestão do presidente Francisco José Cardoso Júnior era a de que ao europeu quando pretendesse imigrar para a região amazônica não lhe fosse imposto um núcleo para estabelecer-se e nem mesmo lhe exigisse a condição de agricultor como requisito. Caso pretendesse trabalhar na lavoura caberia então ao governo provincial fornecer a ele as condições necessárias para isso. Infere-se que para esse administrador se fazia necessário antes de tudo o próprio povoamento da região como solução para a propalada escassez de mão de obra na agricultura local.

Por sua vez, na República também houve uma preocupação com a propaganda responsável por atrair trabalhadores estrangeiros ao Pará, uma vez que muitas colônias foram criadas após 1889 e elas precisavam de colonos. Assim como no Império, também na República o imigrante europeu continuava sendo o preferido do governo, em geral pelas mesmas razões já apontadas. Contudo, essas preocupações com o perfil do imigrante que já haviam sido levantadas por Sant'Anna Nery ${ }^{41}$ surgem com intensidade nos discursos dos governadores. É exemplar nesse sentido o receio do governador José Paes de Carvalho quando, ao se dirigir à Assembleia Legislativa, pediu o apoio necessário para realizar reformas na lei de imigração, uma vez que "a debandada e a inconstância das primeiras levas de imigrantes" era um dos problemas na constituição dos núcleos coloniais. Para tanto, propõe uma reforma da lei que ora vigorava, ou seja, a Lei n. ${ }^{\circ} 223$, de 30 de junho de 1894.

Diversos embates sociais contribuíram para o fracasso desse projeto de colonização. Sem dúvida alguma, foram as dificuldades enfrentadas pelos colonos que contribuíram para esse malogro. O abandono, por parte de inúmeros colonos, nacionais e estrangeiros, dos lotes que ocupavam em diversos núcleos evidenciou esse insucesso. Colonos como Luiz Gonzaga de Freitas Uchoa, que residia no espaço agrícola Itaujary, localizado no município de Monte Alegre, levantaram abaixo-assinado pedindo o título definitivo dos lotes que ocupavam independente de qualquer pagamento, uma vez que haviam chegado com a promessa da gratuidade das terras que ocupassem. ${ }^{42}$

José Paes de Carvalho considerava que muitos trabalhadores estrangeiros que chegavam a Belém eram, de alguma forma, alheios ao trabalho agrícola e logo abandonavam as tarefas na lavoura e que, portanto, a culpa seria dos agentes de imigração, sempre preocupados em mandar o maior número de colonos possíveis,

39 Os imigrantes açorianos acabaram não desembarcando do trem que os conduziu até o núcleo que recebeu o nome de "Araripe". Aquele espaço agrícola não apresentava as condições de instalação esperadas pelos imigrantes, como havia sido prometido pelas autoridades paraenses ainda na Europa.

40 PARÁ. Fala com que o Exmo. Sr. Conselheiro Francisco José Cardoso Júnior, $1^{\circ}$ Vice-presidente da Província do Pará, abriu a $2^{\mathrm{a}}$ sessão da $25^{\mathrm{a}}$ Legislatura da Assembleia Provincial, em 20 de outubro de 1887. Pará: Typ. do Diário de Notícias, 1887, p. 10-11.

41 José Frederico Santana Nery nasceu em Belém do Pará no ano de 1842, mas se mudou muito cedo para a província do Amazonas. Considerado um intelectual, se destacou por divulgar a região amazônica no exterior. Participou de importantes associações europeias como a Associação Literária Internacional onde era vice-presidente - a mesma era presidida por Vitor Hugo. Recebeu o título de barão pelo papa Leão XIII por defender interesses do Vaticano. Por ser ligado à monarquia tornou-se sócio do IHGB. Sobre Santana Nery, ver: COELHO, Anna Carolina de Abreu. "Santa-Anna Nery: um propagandista 'voluntário' da Amazônia (1883-1901)". (Dissertação de mestrado, Universidade Federal do Pará, Belém, 2007).

42 APEP. Caixa 01. Inspetoria de Terras e Colonização. Abaixo-Assinados. 1899-1900. 
uma vez que recebiam por indivíduo, sem levar em consideração a conduta ou ofício que praticavam. Nesse aspecto, a reforma estabelecia que a propaganda ${ }^{43}$ na Europa não poderia "continuar à mercê de agentes e subagentes dos contractantes da immigração, cujos interesses nem sempre estão de accordo com os do Estado". Em sua opinião, a publicidade deveria ficar a cargo "das autoridades locaes e consulados, por agentes idôneos de nomeação e demissão do governo". 44 Muitas vezes os agentes de imigração e as próprias companhias de colonização realizavam falsas propagandas sobre o Brasil, e nesse caso, o Pará seguramente não ficaria de fora do falso imaginário desses sujeitos, captando assim muitos interessados em embarcar, fossem conhecedores da lavoura ou não, de idônea conduta ou não. ${ }^{45}$

Em uma série de artigos publicados no jornal A Província do Pará, de autoria de Domingos Antônio Raiol, o barão de Guajará, o mesmo destaca que um dos principais fatores responsáveis pelo sucesso da imigração na província de São Paulo seria a grande propriedade, antes condenada como "símbolo prejudicial de monopólio" e que agora tem servido "de instrumento poderoso para levar a cabo a propaganda de imigração". Segundo ele, os grandes capitalistas agrários são os principais responsáveis, porque mandam à Europa "commissários hábeis e honestos contratar trabalhadores nos principais centros de população agrícola". Diferentemente das queixas feitas pelo governador José Paes de Carvalho, em São Paulo, os imigrantes que chegavam eram "escolhidos d'entre os homens mais activos e morigerados e não d'entre os vagabundos, ébrios e petroleiros que atravancam as ruas das capitaes europêas". O barão de Guajará ainda lembrou os esforços empreendidos pela Sociedade Promotora de Imigração, ${ }^{46}$ criada na capital paulista, como responsável direta pelos bons resultados alcançados, que buscava "a introducção de colonos escolhidos, moralisados e laboriosos". E, como no período em que Tristão de Alencar Araripe foi presidente da província do Pará (1885-1886), foi criado um guia aos imigrantes que serviria de propaganda para essa região, Domingos Antônio Raiol destacou que também a província de São Paulo criou um guia intitulado Província de S. Paulo, "com interessantes notícias sobre aquellas regiões, livro que foi escripto em portuguêz e traduzido em allemão e

43 O objetivo dos agentes públicos paraenses, fossem provinciais ou republicanos, com a propaganda realizada na Europa por meio de livros, panfletos, exposições ou mesmo pela atuação de agentes de imigração contratados para arregimentar imigrantes era de positivar "o solo, o clima, a floresta, os produtos agrícolas e todos os aspectos econômicos e sociais de maneira que despertassem interesse dos europeus em embarcarem rumo ao Pará". No final do período provincial, José Frederico Sant'Anna Nery se destacou em seu empenho em promover uma propaganda na Europa que pontuava as qualidades naturais, econômicas e sociais do Pará. Embora a propaganda tenha sido financiada a partir dos lucros com a exportação da borracha, a predileção era mesmo por agricultores. Ver: SANTOS, Francisnaldo Sousa. Ações colonizadoras em descompasso: legislação, propaganda e atuação de colonos estrangeiros e nacionais nos últimos anos do Império e início da República no Pará. (Dissertação de mestrado, Universidade Federal do Pará (UFPA), Belém, 2016), p. 62-74.

44 PARÁ. Mensagem dirigida ao Congresso do Estado do Pará pelo Dr. José Paes de Carvalho, governador do Estado do Pará, em 15 de abril de 1898, apresentando a proposta de orçamento da receita e despesa para o exercício de 1898-1899. Belém: Typ. Diário Oficial, 1898, p. 18.

45 MAIA, Fernanda Paula Sousa. A emigração para o Brasil no discurso parlamentar oitocentista. Revista População e Sociedade: A emigração portuguesa para o Brasil, $n^{\circ} 14 / 15$, parte I. Porto, Portugal: Edições Afrontamentos, CESEPE, 2007, p. 56.

46 Zuleika Alvim aponta que a Sociedade Promotora da Imigração, criada em 1886 pelos fazendeiros Martinho Prado, Nicolau de Sousa e Rafael de Barros, encerrou suas atividades em 1895. A autora afirma que, enquanto funcionou, "entraram em São Paulo 480.896 imigrantes, dos quais 353.139 eram italianos". Desse total, "220 mil chegaram por intermédio da SPI". Esses bons números teriam sido possíveis depois que Caetano Pinto, o agente mais importante da Sociedade foi "autorizado a prometer aos imigrantes potenciais, em seus folhetos de propaganda, passagem gratuita do porto de embarque à localidade escolhida como destino, alimentos, sementes, alimentos por mais de seis meses e ainda a esperança de se tornarem proprietários". ALVIM, Zuleika Maria Forcione. "O Brasil italiano (1880-1920)". In: FAUSTO, Boris. (Org.) Fazer a América. A imigração em massa para a América Latina. 2 ed. São Paulo: EDUSP, 2000, p. 395. 
italiano, sendo a sua tiragem de 80 mil exemplares". Esse livro tinha como objetivo promover uma imagem positiva de São Paulo na Europa, com uma propaganda que atraísse famílias de agricultores. Como resultado "milhares de immigrantes pediram logo passagens ao director que então se achava na Itália". Apenas da região norte da Península Itálica, os pedidos alcançavam 50 mil pessoas e logo chegou aos 70 mil. Essas pessoas eram constituídas de "camponezes agricultores, constituindo famílias; não pediam, suplicavam como acto de caridade bilhetes gratuitos de passagens". 47

Fica claro, pelas fontes oficiais, a intenção dos governadores Lauro Sodré e José Paes de Carvalho de combater uma propaganda nociva às pretensões de colonização e povoamento com outra propaganda que desconstruísse aquela que criava naquele momento uma imagem distorcida da realidade amazônica. Não somente da natureza em si, mas também dos sujeitos que poderiam contribuir com esse citado projeto, entre eles o trabalhador nacional. Para ele, um dos grandes problemas a serem enfrentados era aquela propaganda que buscava

desacreditar o trabalho nacional, esquecendo todas as suas qualidades e assignalando tão somente os seus defeitos, que aliás não lhe são intrínsecos, mas resultantes da situação precária em que vivem, privados de todos os meios indispensáveis ao desenvolvimento do civismo, a cultura moral e a compreensão das utilidades múltiplas, a que o devotamento ao trabalho sabe conduzir. ${ }^{48}$

O povoamento da região amazônica sempre esteve voltado para o imigrante, sobretudo quando se pensava no trabalho com a agricultura, por serem eles tidos como conhecedores de técnicas agrícolas que trariam o progresso e o desenvolvimento para a produção de alimentos. Em decorrência dessa predileção pelo colono estrangeiro, o trabalhador nacional passou a ser alvo de uma propaganda que os marginalizava. Contudo, a fala acima mencionada do governador José Paes de Carvalho parece denotar um olhar diferenciado sobre o trabalho nacional até então negligenciado. Nesse sentido, é interessante observar que no dia seguinte a esse discurso anteriormente transcrito, o mesmo governador continuou a demonstrar sua indignação contra a propaganda que atacava a imagem do trabalhador local. Segundo ele, os migrantes, eram "victimas de uma propaganda ilegítima que os tem procurado desconceituar". Na opinião do governador, era, naquele momento, criada uma imagem que não favorecia o trabalhador nacional, ou seja, um tipo de propaganda que não aponta nesse trabalhador aquilo que tem "de prestimoso e só realçando seus defeitos". Defeitos que não seriam inerentes a ele, "mas do abandono em que foram deixados". Essa indignação fica evidente quando o governador confessa-se "contrário a essa antipatriótica e errônea propaganda, para a qual os trabalhadores nacionaes são inaptos ou incapazes de produzir a riqueza do paiz".49

Fosse com colonos nacionais ou estrangeiros, o certo é que as terras devolutas, especialmente na região da estrada de Bragança, deveriam ser povoadas para garantir, como consequência, uma produção agrícola que abastecesse os mercados belenenses, pois como afirma Sidiana Macedo, "o abastecimento da cidade de Belém em grande medida provinha então dos interiores". Segundo a

47 A Província do Pará. Belém, 02 de mar. 1889, p. 2.

48 A Província do Pará. Belém, 02 de mar. 1889, p. 2.

49 PARÁ. Mensagem dirigida ao Congresso do Estado do Pará pelo Dr. José Paes de Carvalho, em 2 de fevereiro de 1897. Belém: Typ. Do Diário Oficial, p. 21. 
autora, as embarcações que chegavam aos portos da cidade de Belém provinham de "Cametá, Marajó, Monsarás, Óbidos, Santarém, Bragança, Vigia e outros lugares carregados dos mais variados produtos para abastecer o mercado, bem como para a exportação"..$^{0}$ Também com essa mesma linha de raciocínio, Elis Regina Vieira deixa evidente a ligação que existe entre a floresta, as áreas rurais e a capital. A autora, se referindo à conexão entre esses espaços, aponta que a principal ligação entre eles está na importância que diversas áreas rurais como os núcleos agrícolas, por exemplo, "tinham para as atividades econômicas da capital paraense".51

De qualquer forma, a política adotada na República para atrair imigrantes, sobretudo na primeira década, se não deu os resultados esperados pelos governos no campo da agricultura, ao menos indiretamente ajudou outros setores como o extrativismo. Mas isso não significa dizer que os colonos abraçaram o extrativismo. Quanto a essa questão, não é possível estabelecer uma dicotomia tão exata entre seringueiros e agricultores, ou seja, muitas vezes o agricultor da região Bragantina era também aquele que extraía madeira. Dessa forma, autores como Roberto Santos, por exemplo, lembram que, com o fracasso de muitos núcleos coloniais, vários estrangeiros se dirigiram aos seringais, ajudando a solucionar o problema com a escassez de trabalhadores que nas últimas décadas do século XIX começava a afetar a produção do látex, corroborando assim com essa visão dicotômica desse sujeito. $\mathrm{O}$ autor indica ainda que, embora boa parte dos nordestinos ${ }^{52}$ que migraram para o Pará tenha permanecido em parte do norte do estado, número significativo também acabou indo para os seringais. ${ }^{53}$

\section{Considerações finais}

O trabalhador agrícola pretendido pelo poder público provincial/estadual no Pará sempre foi o imigrante, seja por ser considerado mais afeito ao trabalho ou porque, na visão dos governantes, traria consigo novas técnicas e conhecimentos agrícolas. Nesse sentido, Natália Cruz destaca que a vinda do imigrante "foi muito estimulada porque as elites do período", para além das questões econômicas e produtivas, almejavam também "a formação de uma futura nacionalidade brasileira baseada na raça e na cultura brancas". Dentro desse contexto, em fins do século XIX intensificou-se o debate "em torno do imigrante ideal ou do tipo racial mais adequado para purificar a 'raça brasileira' e engendrar uma identidade nacional". ${ }^{54}$ Havia ainda aqueles estrangeiros que de certa forma não eram apreciados. Entre esses imigrantes pouco desejados pelos defensores da colonização, Martins aponta, entre outros estrangeiros, que havia um grande preconceito contra chineses e turcos, "com os quais, entendiam, não seria possível instituir no país uma agricultura moderna". 55

A reflexão acerca do ordenamento jurídico cunhado após 1889 e também das estruturas burocráticas criadas nos leva a acreditar na existência de uma crítica

50 MACEDO, Sidiana da Consolação Ferreira de. "Daquilo que se come: uma história do abastecimento e da alimentação em Belém (1850-1900)". (Dissertação de mestrado, Universidade Federal do Pará, Belém, 2009), p. 32.

51 VIEIRA; LACERDA. "O Celeiro da Amazônia", p. 158-159.

52 Usamos aqui a expressão "nordestinos", pois assim Roberto Santos se refere na obra citada. Mas devemos lembrar que em geral a documentação se refere a esses migrantes como cearenses, independente da província de origem. Ver: NUNES, Francivaldo Alves. "Sob o signo do moderno cultivo: estado imperial e agricultura na Amazônia". (Tese de doutorado, Universidade Federal Fluminense, 2011), p. 304.

53 SANTOS, Roberto. História econômica da Amazônia (1800-1920). São Paulo: T.A. Queiroz editor, 1980, p. 87.

54 CRUZ, Natália. Imigração. In.: MOTTA, Marcia (org). Dicionário da Terra. Civilização Brasileira, 2005, p. 248.

55 MARTINS, José de Sousa. A imigração e a crise do escravismo. São Paulo: Pioneira, 1973, p. 175. 
ao modelo de imigração que vinha sendo desenvolvido durante o Império como solução para o problema do abastecimento da capital Belém a partir da mão de obra a ser instalada nos espaços agrícolas constituídos, principalmente na região nordeste do estado. Contudo, a colonização planejada nos anos finais da província e na primeira década da República pautada com prioridade no trabalhador estrangeiro, fosse com o objetivo de trazer para a região Bragantina o pretenso conhecimento técnico e aptidão desse imigrante para o trabalho na lavoura ou o objetivo de simplesmente povoar uma área vista como altamente propícia para a agricultura - ou mesmo os dois objetivos concomitantes - evidenciou a marginalização do trabalhador nacional, o roceiro, autor de "práticas tidas como rotineiras e irracionais". ${ }^{56}$

Enviado: 19/06/2016

Aprovado: 10/12/2016

56 ESTEVES. A "Reconstrução radical da agricultura", p. 7. 